\title{
Neuroparsins, a family of conserved arthropod neuropeptides
}

\author{
Liesbeth Badisco *, Ilse Claeys, Tom Van Loy, Matthias Van Hiel, Vanessa Franssens, \\ Gert Simonet, Jozef Vanden Broeck
}

Animal Physiology and Neurobiology, K. U. Leuven, Belgium

Received 15 September 2006; revised 14 March 2007; accepted 19 March 2007

Available online 24 March 2007

\begin{abstract}
Different neuroparsin variants were initially identified as anti-gonadotropic peptides from the pars intercerebralis-corpora cardiaca complex of the migratory locust, Locusta migratoria, and further studies revealed the pleiotropic activities of these peptides. Subsequently, additional neuroparsin-like peptides were discovered from other arthropod species. Studies in mosquitoes and locusts suggest that members of this conserved peptide family are involved in the regulation of insect reproduction and can even serve as molecular markers of the fascinating biological process of locust phase transition. Sequence analysis and multiple alignments revealed pronounced sequence similarities between arthropod neuroparsins and the N-terminal, growth factor binding region of vertebrate and mollusc insulin-like growth factor binding proteins (IGFBP). This observation led to the hypothesis that neuroparsins might interact with endogenous insulin-related peptides. The present paper gives an overview of several neuroparsin family members that have hitherto been described in insects, as well as of a number of newly identified neuroparsin precursors from other species.
\end{abstract}

(C) 2007 Elsevier Inc. All rights reserved.

Keywords: Growth factor; Insect; Insulin; Parsin

\section{Introduction}

As in most other animal phyla, neuropeptides constitute the most diverse category of extracellular messenger molecules in arthropods and play a key role in the regulation of important physiological processes, such as metabolism, growth and development, homeostasis, reproduction and behaviour. Sequence comparisons have already revealed the existence of several structurally and evolutionary conserved neuropeptide families, even across the protostomian and deuterostomian barrier (Vanden Broeck, 2001).

One of the milestones in insect endocrinology was the discovery of several so-called 'parsins', a category of large neuropeptides (i.e. small proteins) that were initially discovered in the pars intercerebralis-corpora cardiaca neurohaemal complex of locusts and which comprise the neuroparsins (NPs), the insulin-related peptides (IRPs),

\footnotetext{
* Corresponding author. Fax: +3216323902.

E-mail address: liesbeth.badisco@bio.kuleuven.be (L. Badisco).
}

the ovary maturating parsins (OMPs) and the pacifastins. The purification of Locusta migratoria NP (Girardie et al., 1989)-later also identified in the desert locust, Schistocerca gregaria (Girardie et al., 1998; Janssen et al., 2001; Claeys et al., 2003) — was based on the discovery of an inhibitory activity of vitellogenesis in migratory locusts. On the other hand, the 'ovary ecdysteroidogenic hormone' $(\mathrm{OEH})$, a mosquito NP-like factor, displayed gonadotropic and ecdysteroidogenic activity in adult female mosquitoes (Brown et al., 1998). An invertebrate substance with insulin-like activities was first demonstrated in 1923, in the bivalve mollusc Mya arenaria (Collip, 1923; Falkmer et al., 1973). By the use of bioassays and immunological detection methods, insulin-like substances could be demonstrated in various species of coelenterates (Davidson et al., 1971), mollusks (Plisetskaya et al., 1978), annelids (Leroith et al., 1981), arthropods (Van Noorden and Falkmer, 1980) and echinoderms (Wilson and Falkmer, 1965). Since a small Bombyx mori prothoracicotropic hormone showed homology to insulin, determination of its amino acid 
sequence represented the first structural identification of an insect/invertebrate IRP (Nagasawa et al., 1980). Later, IRPs have also been identified from other insects and various studies have demonstrated the importance of the insulin/IRP signalling pathway in a variety of physiological processes, including growth and reproduction (as reviewed by Claeys et al., 2002). Lom-OMP, the L. migratoria 'ovary maturating parsin', was the first discovered insect gonadotropin (Girardie et al., 1991). It stimulates vitellogenin synthesis in locusts, presumably via an induction of ovarian ecdysteroid production. Nevertheless, the evolutionary importance of this peptide remains enigmatic, since, except for the desert locust, S. gregaria (Girardie et al., 1998), at present no OMP homologues have been identified from other insects. The first locust members of the 'pacifastin family' of peptides were also derived from the pars intercerebralis-corpora cardiaca complex (Nakakura et al., 1992). These peptides act in vitro as potent inhibitors of serine proteases and of mammalian $\mathrm{N}$-type $\mathrm{Ca}^{2+}$ ion channels.

Although parsins were initially associated with insect reproduction, they were also suggested to be markers in the process of locust 'phase transition' (Ayali et al., 1996; De Loof et al., 2006). This term refers to the transition between the two extreme phases desert locusts can adopt, i.e. the solitary and gregarious phase. It designates a biological process leading to the formation of locust swarms that-occurring with irregular intervals of 10-20 years-represent a threat to the agricultural production in large areas of Africa and Asia. The transition not only results in behavioural changes (solitary versus swarming), but also leads to differences in colour patterns, size, weight, development and reproduction (Bouaichi et al., 1995; Collet et al., 1998; Pener and Yerushalmi, 1998). Since the two phases display clear differences in their reproductive physiology and since neuroparsins were identified as regulators of insect reproduction, it seems likely that neuroparsins might play a role in the context of phase transition too.

This review focuses on NPs and refers to their initial discovery in L. migratoria and subsequent identification and study in other insects. Also, a number of novel neuroparsin-like peptides from other arthropod species are presented.

\section{Locusta migratoria neuroparsins (Lom-NPs)}

Neuroparsins were initially isolated from the corpora cardiaca $(\mathrm{CC})$ of the migratory locust, L. migratoria. Neuroparsin A (NPA) consists of 83 amino acid (AA) residues, but coexists with four isoforms, NPA-I-IV, which can all be found in the CC. Neuroparsin B contains 78 AA, which are also present in the amino acid sequence of NPA, suggesting that NPB is a post-translationally processed product of NPA. The different isoforms of NPA appear to be the intermediary products of the processing steps from NPA to NPB. These neuroparsins exist as monomers, with six intramolecular disulfide bridges. Containing 12 cysteine residues, they belong to the most cysteine-rich neurohormones (Boureme et al., 1989; Girardie et al., 1989; Hietter et al., 1991).

NPA is produced in the A1-type neurosecretory cells of the pars intercerebralis and is subsequently transported via the nervus corporis cardiaci I (NCC-I) to the storage part of the CC, where NPA is gradually converted to NPB. From this location, both NPA and NPB are released into the haemolymph. In 1992, a $1 \mathrm{~kb}$ transcript encoding the NPA precursor, comprising a 22 AA signal peptide and the 83 AA NPA, was cloned and sequenced by Lagueux et al. (Lagueux et al., 1992).

Lom-NP was found to be pleiotropic, since it had antidiuretic (Fournier et al., 1987), anti-gonadotropic, neuritogenic, hypertrehalosemic and hyperlipemic effects. The effects of Lom-NP appeared to be contrary to effects of juvenile hormone $(\mathrm{JH})$. It delayed vitellogenesis and treatment with an anti-NP serum resulted in green pigmentation and accelerated sexual maturation. The same effects were obtained after JH treatment (Girardie et al., 1987). When organotypic cultures of the locust embryonic central nervous system (CNS) were treated with $\mathrm{NP}$, a significant increase in neurite outgrowth was observed. Hence, at least in locusts, NP appeared to act as a neurotogenic factor (Vanhems et al., 1990). Although less potent than adipokinetic hormone (AKH), NP also induced an increase in trehalose and lipid levels in the haemolymph. It was suggested that it might act together with $\mathrm{AKH}$ in the regulation of carbohydrate metabolism (Moreau et al., 1988).

Although initially only a single type of NP (NPA and its processed forms) was characterized in L. migratoria, two additional NPs were identified by means of an in silico search in LocustDB. This database contains a large collection of ESTs, unigenes and their annotation, and has been derived from both solitarious and gregarious fifth-instar heads, hind legs, midguts and whole bodies ( $\mathrm{Ma}$ et al., 2006). The ESTs, with Accession Nos. CO849956 and CO849958, respectively, encode the NP-like peptides Lom-NPP2 and Lom-NPP3, and are represented in Fig. 1.

\section{Schistocerca gregaria neuroparsins (Scg-NPs)}

In 1998, the amino acid sequence of the $S$. gregaria NP $(S c g$-NP) was determined by Girardie et al. $S c g$-NP isoforms result from the gradual conversion of NPA to NPB, as was also demonstrated for Lom-NPA. When comparing Lom-NP and Scg-NP, only 10 mutations and 88\% sequence identity are noticed. This sequence conservation is higher in the N-terminal part (97\%) than in the C-terminal part (78\%). Scg-NPA contains 12 cysteine residues that are shared with Lom-NP and which are involved in the formation of six disulfide bridges. This high level of sequence similarity proves that these neuropeptides belong to the same neurohormone family. $S c g$-NP is also produced in the A1-type neurosecretory cells of the pars intercerebralis (Girardie et al., 1998). 
A combination of standard PCR (using degenerate primers based on the AA sequence of $S c g$-NPA) and RAcE-PCR led to the identification of four neuroparsin precursors-numbered Scg-NPP1-4 from brain and fat body. Scg-NPP1 and 2, containing 107 and 103 AA, respectively, were identified from brain, whereas $\mathrm{Scg}$ NPP3 and 4, containing 103 and 104 AA, respectively, were identified from fat body. These four neuroparsin precursors have an identical N-terminal part (AA 1-61) and contain at least 10 cysteine residues, which are also shared with Lom-NP. Interestingly, they show sequence similarity with the N-terminal hormone binding domain of vertebrate insulin-like growth factor binding proteins (IGFBPs), which is highly conserved among members of the IGFBP

Amv_NPLP
Rha_NPLP
Lis_NPLP
Pem_NPLP
Lom_NPP1
Scg_NPP1
Lom_NPP2
Scg_NPP4
Lom_NPP3
Scg_NPP2
Scg_NPP3
Cas_NPLP
Cam_NPLP
Acg_NPLP
Car_NPLP
Maj_NPLP
Hoa_NPLP
Bom_NPLP
IGFBP7
Hal_perl
Apm_NPP
Soi_NPLP
Liv_NPLP1
Lip_NPLP
TrC_NPLP
Ang_OEH
Aea_OEH
consensus

Amv NPLP

Rha_NPLP

Lis NPLP

Pem NPLP

Lom NPP1

Scg_NPP1

Lom NPP2

$\mathrm{Scg}$ NPP4

Lom NPP3

Scg NPP2

Scg NPP3

Cas NPLP

Cam NPLP

Acg_NPLP

Car NPLP

Maj_NPLP

Hoa NPLP

Bom NPLP

I GFBP 7

$\mathrm{Hal}$ perl

Apm_NPP

Soi_NPLP

Liv NPLP1

Lip NPLP

Trc_NPLP

Ang_OEH

Aea $\mathrm{OEH}$

consensus
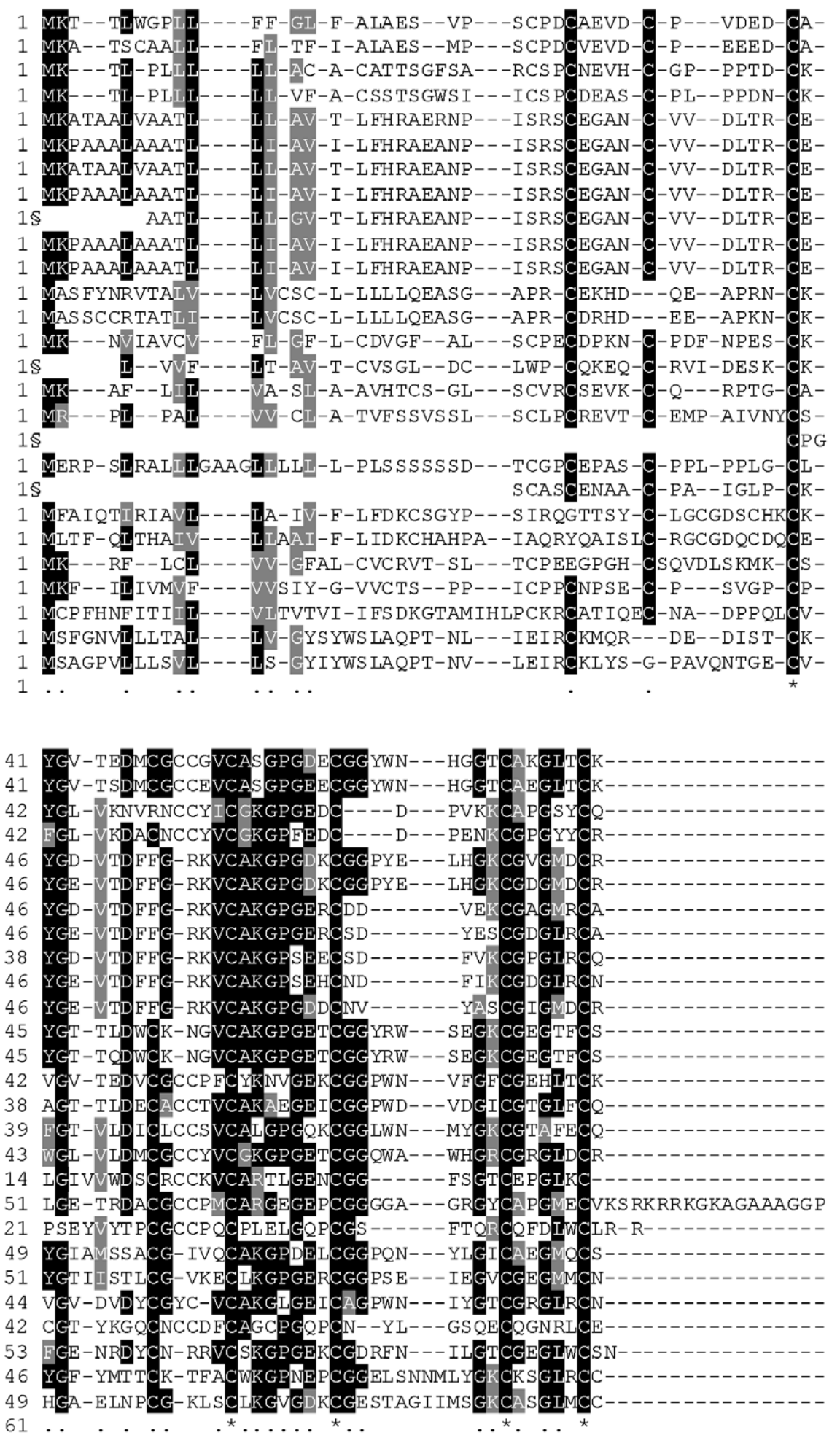
family. Highest sequence similarity was shown with IGFBP7 (Janssen et al., 2001; Claeys et al., 2003). Hence, it was suggested that these NPs interact with an endogenous IRP. There is evidence that IRPs are also involved in the regulation of insect reproduction (Riehle and Brown, 1999), while vertebrate IGFs and some IGFBPs are important regulators of gonadal steroidogenesis and follicle growth (Monget et al., 1996; Yoshimura, 1998; Webb et al., 1999; Arraztoa et al., 2002).

In order to perform a comparative analysis of the relative abundance of $S c g$-NPP1-4 transcripts in both gregarious and solitarious desert locusts, a quantitative real-time RT-PCR assay was performed by Claeys et al. (Claeys et al., 2005). Relative transcript levels were determined in samples derived from brain, fat body, foregut, midgut, hindgut, gonads and male accessory glands of mature locusts. In gregarious males and females, Scg-NPP1 and $S c g$-NPP2 transcript levels were only detected in the brain, whereas both transcripts were also detected in the fat body of isolated-reared desert locusts, rendering these transcripts interesting candidates as molecular markers of phase polyphenism. $S c g$-NPP3 and $S c g$-NPP4 transcripts were abundantly detected in various tissues of gregarious locusts, more specifically in male and female brain, fat body, testis and male accessory glands. Remarkably, none of these transcripts was detected in female gonads. Phaserelated differences were observed for all $S c g$-NPP transcript levels, especially for the $S c g$-NPP3 mRNA, which reaches much higher levels (>50 times) in gregarious male and female fat body and in male brain and accessory glands, than in the corresponding tissues of solitarious animals. In summary, $S c g$-NPP1 and 2 are more abundant in solitarious locusts, whereas Scg-NPP3 and 4 are more abundant in gregarious locusts. These findings were the first indications of a phase-dependent transcriptional regulation of Scg-NPPs gene expression (Claeys et al., 2005).

Study of the temporal regulation of specific transcript levels suggested a relationship between the reproductive cycle - of both the solitary and gregarious locusts - and
$S c g$-NPP transcript levels in the fat body and/or the brain. Although the exact mode of action of neuroparsins remains to be elucidated, there are very few genes known in insects of which the transcripts are so drastically regulated during the period of gonadal and sexual maturation. These findings suggest that the neuroparsins might play an important role in the physiology of reproduction.

Both the "classic" insect hormones juvenile hormone $(\mathrm{JH})$ and 20-hydroxyecdysone (20E) are considered as important regulators of insect reproduction. Based on this fact, the possible relationship between these hormones and the expression of the different neuroparsin precursors in the desert locust was studied by analyzing neuroparsin precursor transcript levels in response to hormonal treatments (Claeys et al., 2006). Except for Scg-NPP1, a significant $\mathrm{JH}$-dependent induction of the NP precursor transcript levels could be observed in the brain ( $S c g$-NPP2) and the fat body ( $S c g$-NPP3-4) of male locusts. Female locusts, however, showed less pronounced effects. Treatment with $20 \mathrm{E}$ was able to induce $S c g$-NPP2, $S c g$-NPP3 and $S c g$-NPP4 expression in the gonads of both males and females. This is a remarkable fact, as no neuroparsin expression (except for Scg-NPP3-4 in testes) is observed in gonads without 20 E treatment. The absence of transcriptional Scg-NPP1 regulation during the reproduction cycle and after $\mathrm{JH}$ or $20 \mathrm{E}$ treatment, suggests that it may not be tightly linked to the control of reproduction in gregarious locusts (as the effects of $\mathrm{JH}$ and $20 \mathrm{E}$ treatments have hitherto only been studied in gregarious locusts). Perhaps it is involved in more general physiological processes, which may be related to some of the biological activities previously reported for Lom-NP. Nevertheless, the situation may be different in solitarious locusts, since there is evidence that in these animals $S c g-N P P 1$ transcripts are regulated in function of the reproduction cycle.

Injection experiments with $\mathrm{JH}$ and $20 \mathrm{E}$ revealed that the expression of several members of the neuroparsin family in $S$. gregaria is under hormonal control. Once more, the study supports the hypothesis that the occurrence of some

Fig. 1. Multiple sequence alignment of the N-terminal region of neuroparsin-like peptides of several arthropod species and human insulin-like growth factor binding protein 7 (IGFBP7). The alignment was performed by means of ClustalW at BCM Search Launcher (http://searchlauncher.bcm.tmc.edu/ multi-align/multi-align.html) (as a weight matrix 'pam' was chosen, other parameters were set at default values). Highly conserved residues are highlighted in black. Residues that are similar to the column's consensus are shaded. The consensus line is represented by symbols: '*' representing a particular position at which an amino acid is completely conserved, '’' representing a position for which a consensus is defined, but at which not all amino acids are equal to the consensus. Sequences starting with the '§' symbol are hitherto incomplete. Abbreviations: Lis-NPLP, Litopenaeus setiferus neuroparsin-like peptide (EST-derived, GenBank: BE846730); Pem-NPLP, Penaeus monodon NPLP (EST-derived, GenBank: BI784456); Amv-NPLP, Amblyomma variegatum NPLP (EST-derived, GenBank: BM291935); Rha-NPLP, Rhipicephalus appendiculatus NPLP (EST-derived, GenBank: CD796554); LomNPP1, Locusta migratoria neuroparsin precursor 1 (GenPept: CAA76829); Lom-NPP2, L. migratoria NPP2-3 (EST-derived, GenBank: CO849956, CO849958); Scg-NPP1-4, Schistocerca gregaria NPP1-4 (GenPept: CAC38869, CAC38870, CAC82521, CAC82522); Cas-NPLP, Callinectes sapidus NPLP (EST-derived, GenBank: CV031136, CV161870); Cam-NPLP, Carcinus maenas NPLP (EST-derived, GenBank: DN551462, DN634631); AcgNPLP, Acanthoscurria gomesiana NPLP (EST-derived, GenBank: DR444734); Bom-NPLP: Bombyx mori NPLP (EST-derived, GenBank: BP122533); IGFBP, human insulin-like growth factor binding protein (GenPept: NP001544); Car-NPLP, Carcinoscorpius rotundicauda NPLP (EST-derived, GenBank: CK086959); Hoa-NPLP, Homarus americanus NPLP (EST-derived, GenBank: CN854288); Hal-perl, Haliotis laevigata perlustrin (GenPept: P82595); Apm-NPP, Apis mellifera NPP (bee brain EST-derived fragment, GenBank: BI505843); Soi-NPLP, Solenopsis invicta NPLP (EST-derived, GenBank: EE147102); Maj-NPLP, Marsupeneaus japonicus NPLP (EST-derived, GenBank: AU176073); Liv-NPLP, Litopenaeus vannamei NPLP (ESTderived, GenBank: BE188518); Trc-NPLP, Tribolium castaneum NPLP (derived from genomic fragment, BeetleBase: contig2033_contig2812); Ang-OEH, Anopheles gambiae ovary ecdysteroidogenic hormone (GenPept: EAA06579); Aea-OEH, Aedes aegypti OEH (GenPept: AAC38958); Lip-NPLP: Limulus polyphemus NPLP (EST-derived, GenBank: AF337906, AAK15535). 
NPs is closely associated with the endocrine regulation of locust reproduction. Literature data indicate that the levels of $\mathrm{JH}$ and $20 \mathrm{E}$ undergo important changes in locust haemolymph during adult life (Tawfik et al., 1996, 1997, 1999, 2000). Interestingly, the haemolymph titre of ecdysteroids in adult $S$. gregaria reached significantly higher peak values in isolated than in crowded animals (Tawfik et al., 1996, 1997). On the contrary JH titres are usually higher in gregarious than in solitarious individuals (Tawfik et al., 2000). These observations could lead to the hypothesis that high $S c g$-NPP3-4 levels, as observed in gregarious female fat body samples, may result from increased levels of $\mathrm{JH}$, while these transcripts appear to be unaffected by the high peak values of ecdysteroids in the haemolymph of isolated-reared females. However, the regulation of $\mathrm{Scg}$ NPP expression is likely to be more complex, for instance in the brain where, in addition to circulating hormones, it probably also depends on neuronal control in the pars intercerebralis.

\section{Ovary ecdysteroidogenic hormone (OEH)}

OEH has initially been identified from the yellow fever mosquito, Aedes aegypti, as a neurohormone that is released from the brain in response to a blood meal (Brown et al., 1998). In females, it is produced in two or three pairs of median neurosecretory cells in the brain and consequently transported to the $\mathrm{CC}$. There appears to be only one single copy of the gene, although more alleles exist. The OEH precursor consists of 149 amino acid residues, including a 22 AA signal peptide, followed by a 83 AA bioactive peptide. The bioactive peptide sequence shows the highest sequence similarity (29\%) to Lom-NPA, including eight similarly positioned cysteine residues. This suggests that $\mathrm{OEH}$ is a member of the neuroparsin family of neurohormones (Fig. 1).

OEH is released into the haemolymph in response to a blood meal and stimulates the ovaries to secrete ecdysteroid hormones, which at their turn modulate yolk protein synthesis in the fat body. Exerting gonadotropic and ecdysteroidogenic activities in mosquitoes, $\mathrm{OEH}$ was among the first gonadotropins to be identified from invertebrates. Furthermore, vertebrate insulin was also shown to stimulate ecdysteroidogenesis in mosquitoes, suggesting a parallel role of NP/OEH- and IRP-like peptides in (mosquito) ovarian ecdysteroidogenesis (Riehle and Brown, 1999).

Evidence for an OEH homologue in the African malaria mosquito, Anopheles gambiae, was given by Riehle et al. (Riehle et al., 2002) by whole-mount immunocytochemistry using antisera against the entire Ae. aegypti $\mathrm{OEH}$ sequence. The same study revealed similar OEH distribution in both mosquito species. Whereas OEH was initially detected in median neurosecretory cells and in axons extending to the $\mathrm{CC}$, it was also observed in the ventral nerve cord and in the guts of both sexes of Ae. aegypti and An. gambiae larvae and adults. This is not exceptional, since neurosecretory cells and midgut endocrine cells are proven to be sources of diverse neuropeptides (Gade et al., 1997). There appear to be two main OEH neuroendocrine release sites, being the axonal region of the medial neurosecretory cells that extend from the $\mathrm{CC}$ and along the midgut, and the abdominal perivisceral organs. Evidence for the presence of OEH in the axonal network on the hindgut of An. gambiae suggests that the peptide might also be involved in regulation of water balance or movement of food through the gut. Similar localization of OEH in different tissues, stages and sexes of both mosquito species suggests that the function of this neuropeptide is conserved within mosquitoes and that it is involved in the regulation of diverse processes during reproduction and development (Brown and Cao, 2001). Meanwhile the An. gambiae OEH (Fig. 1) has been identified from the corresponding genome and EST database (Claeys et al., 2003).

\section{Neuroparsin-like peptides (NPLPs) in other species}

Bourême et al. demonstrated NPLPs in CC-extracts of the cockroach species, Blaberus craniifer and Leucophaea maderae. Like Lom-NP, these NPLPs were proven to stimulate rectal water reabsorption in vitro and in vivo in cockroaches as well as in migratory locusts (Boureme et al., 1989). By an immunohistochemical study (using anti-NP serum) of brain and/or CC of several insect species, Tamarelle and Girardie (1989) demonstrated that all tested species of Odonata, Dictyoptera, Isoptera and Orthoptera showed immunoreactivity and hence were supposed to express NP-like peptides. Production of these NPLPs also appeared to occur in the A1type neurosecretory cells of all these species. In addition to these insect orders, only two Diptera (Ae. aegypti and An. gambiae) were shown to express NPLPs, namely the OEHs. NP immunostaining was also demonstrated in two annelid species (Tamarelle and Girardie, 1989). In 1990, Tamarelle et al. demonstrated NP-like immunoreactivity in the brain of the german cockroach, Blatella germanica. Immunoreactive cell bodies were observed in the median part of the protocerebrum and in axons terminating in the nervous part of the $\mathrm{CC}$ and between the intrinsic neurosecretory cells (Tamarelle et al., 1990).

Perlustrin, a peptide showing homology to the N-terminal part of vertebrate IGFBP has been identified from the mollusc, Haliotis laevigata. Despite the long evolutionary distance between mollusks and vertebrates, this peptide shows $40 \%$ sequence homology to vertebrate IGFBPs, including 12 conserved cysteine residues. Moreover, perlustrin was demonstrated to bind IGFs with approximately the same affinity as IGFBP-5, but binding of bovine insulin occurred with a much lower affinity. This was the first evidence of IGFBP-like peptides in mollusks (Weiss et al., 2000, 2001).

\section{Neuroparsin-like peptides (NPLPs) from DNA databases}

Neuroparsin-like peptides have first been described and studied in locusts and mosquitoes, but have now been 
Table 1

EST databases containing NPLP encoding transcript sequences

\begin{tabular}{|c|c|c|}
\hline Organism & cDNA library & Reference \\
\hline Carcinus maenas & $\begin{array}{l}\text { Gills, hypodermis, heart, hepatopancreas, antennal gland, brain, ovary, testis and skeletal muscle collected } \\
\text { from animals acclimated to } 35 \% \text { and } 10 \% \text { salinity }\end{array}$ & $\begin{array}{l}\text { Towle and Smith } \\
\text { (2006) }\end{array}$ \\
\hline Homerus americanus & $\begin{array}{l}\text { Gill, epipodite, branchiostegite, heart, hepatopancreas, antennal gland, brain, ovary, testis and skeletal } \\
\text { muscle collected from intermolt and post-molt lobsters }\end{array}$ & $\begin{array}{l}\text { Towle and Smith } \\
(2006)\end{array}$ \\
\hline Callinectes sapidus & Gill and hypodermis collected from animals acclimated to $35 \%$ and $5 \%$ salinity & Unpublished \\
\hline $\begin{array}{l}\text { Rhipicephalus } \\
\text { appendiculatus }\end{array}$ & Salivary glands of 4-day fed female adults & Nene et al. (2004) \\
\hline $\begin{array}{r}\text { Carcinoscorpius } \\
\text { rotundicauda }\end{array}$ & $\begin{array}{l}\text { Amebocytes and hepatopancreas from pooled cDNAs from } 3 \text { and } 6 \text { hours after a Pseudomonas infection } \\
\text { and from naive crabs }\end{array}$ & Ding et al. (2005) \\
\hline Solenopsis invicta & $\begin{array}{l}\text { Eggs, small, medium-sized and sexual larvae, pupae, adult males, females and queens (virgin/mated) from } \\
\text { both monogynous and polygynous colonies collected at Georgia, USA }\end{array}$ & $\begin{array}{l}\text { Wang et al. } \\
(2007 a)\end{array}$ \\
\hline $\begin{array}{l}\text { Acanthoscurria } \\
\text { gomesiana }\end{array}$ & Haemocytes from adults of both sexes, and in the intermolt stage & $\begin{array}{l}\text { Lorenzini et al. } \\
\text { (2006) }\end{array}$ \\
\hline
\end{tabular}

All are publicly accessible via the GenBank database.

discovered in a broad range of other arthropods by in silico data mining approaches. Several genome and EST-projects have generated an increasing number of DNA sequences from various animal sources. Putative NPLP encoding genes and/or ESTs were previously identified from the insects Apis mellifera, An. gambiae and B. mori, from the crustaceans Litopenaeus vannamei, Litopenaeus setiferus, Penaeus monodon and Marsupeneaus japonicus, and from the chelicerates Limulus polyphemus and Amblyomma variegatum (Claeys et al., 2003). However, no NP/OEH-like peptides have hitherto been identified from Drosophila species, which perhaps suggests the loss of the gene in this genus. Beetlebase is an integrated resource for Tribolium genetics, genomics and developmental biology (http:// www.bioinformatics.ksu.edu/BeetleBase/), and has been developed by the KSU Bioinformatics Center, Kansas State University (Manhattan, Kansas, USA). It integrates genomic sequence data of the red flour beetle, Tribolium castaneum, and includes information about genes, mutants, genetics markers, ESTs and publications (Lorenzen et al., 2005; Wang et al., 2007a,b). A 'tblastn' search has been performed against 'All Tribolium sequences', using all known NP(LP) amino acid sequences as a query. The best scoring hit, the genomic fragment 'contig 2033_2812', has been analysed by the 'Augustus' gene prediction tool (http://augustus.gobics.de/) (Stanke et al., 2006). The peptide sequence encoded by the predicted coding sequence is represented in Fig. 1 and displays high similarity to the already known NPs (it is most similar to $S c g$-NPP1), suggesting that it belongs to the neuroparsin family.

EST databases for Carcinus maenas, Homarus americanus, Callinectes sapidus, Rhipicephalus appendiculatus, Carcinoscorpius rotundicauda, Solenopsis invicta and Acanthoscurria gomesiana are publicly accessible via the GenBank database. Information about these databases is provided in Table 1. A 'tblastn' search-using all known amino acid sequences of NP-like peptides as a queryagainst the GenBank 'est' database resulted in hits from these EST databases. The predicted peptide sequences are represented in Fig. 1. The C. maenas, C. sapidus and
$S$. invicta NPLPs show highest sequence similarity scores to $S c g$-NPP1, whereas the $H$. americanus, $R$. appendiculatus, C. rotundicauda and $A$. gomesiana NPLPs show highest similarity scores to mammalian IGFBP7, but all these sequences possess a very similar pattern of Cys residues and belong to the same peptide family.

In conclusion, neuroparsins constitute a fascinating family of well-conserved neuropeptides, now demonstrated to occur in various invertebrates. Moreover, they resemble vertebrate IGFBPs, suggesting that they were already present in the common ancestor of protostomians and deuterostomians.

\section{Acknowledgments}

The authors gratefully acknowledge the Belgian "Interuniversity Poles of Attraction Programme" (IUAP/PAI P6/14), the K.U. Leuven Research Foundation (GOA/ 2005/06) and the Fund for Scientific Research (FWO) for financial support. I.C. obtained a postdoctoral fellowship from the K.U. Leuven Research Foundation; G.S. obtained a postdoctoral fellowship from the IWT; L.B., V.F., T.V.L. and M.V.H. obtained a PhD fellowship from the IWT.

\section{References}

Arraztoa, J.A., Monget, P., Bondy, C., Zhou, J., 2002. Expression patterns of insulin-like growth factor-binding proteins 1, 2, 3, 5, and 6 in the mid-cycle monkey ovary. J. Clin. Endocrinol. Metab. 87, 52205228.

Ayali, A., Pener, M.P., Girardie, J., 1996. Comparative study of neuropeptides from the corpora cardiaca of solitary and gregarious Locusta. Arch. Insect Biochem. Physiol. 31, 439-450.

Bouaichi, A., Roessingh, P., Simpson, S.J., 1995. An analysis of the behavioral-effects of crowding and re-isolation on solitary-reared adult desert locusts (Schistocerca gregaria) and their offspring. Phys. Ent. 20, 199-208.

Boureme, D., Fournier, B., Matz, G., Girardie, J., 1989. Immunological and functional cross-reactivities between locust neuroparsins and proteins from cockroach corpora cardiaca. J. Insect Phys. 35, 265-271. 
Brown, M.R., Cao, C., 2001. Distribution of ovary ecdysteroidogenic hormone I in the nervous system and gut of mosquitoes. J. Insect Sci. $1,1-11$.

Brown, M.R., Graf, R., Swiderek, K.M., Fendley, D., Stracker, T.H., Champagne, D.E., Lea, A.O., 1998. Identification of a steroidogenic neurohormone in female mosquitoes. J. Biol. Chem. 273, 3967-3971.

Claeys, I., Simonet, G., Poels, J., Van Loy, T., Vercammen, L., De Loof, A., Vanden Broeck, J., 2002. Insulin-related peptides and their conserved signal transduction pathway. Peptides 23, 807-816.

Claeys, I., Simonet, G., Van Loy, T., De Loof, A., Vanden Broeck, J., 2003. cDNA cloning and transcript distribution of two novel members of the neuroparsin family in the desert locust, Schistocerca gregaria. Insect Mol. Biol. 12, 473-481.

Claeys, I., Simonet, G., Breugelmans, B., Van Soest, S., Franssens, V., Sas, F., De Loof, A., Vanden Broeck, J., 2005. Quantitative real-time RT-PCR analysis in desert locusts reveals phase dependent differences in neuroparsin transcript levels. Insect Mol. Biol. 14, 415-422.

Claeys, I., Breugelmans, B., Simonet, G., Franssens, V., Van Soest, S., Vanden Broeck, J., 2006. Regulation of Schistocerca gregaria neuroparsin transcript levels by juvenile hormone and 20-hydroxyecdysone. Arch. Insect Biochem. Physiol. 62, 107-115.

Collet, M., Despland, E., Simpson, S.J., Krakauer, D.C., 1998. Spatial scales of desert locust gregarization. Proc. Natl. Acad. Sci. USA 95, 13052-13055.

Collip, J.B., 1923. The demonstration of an insulin-like substance in the tissues of the clam (Mya arenaria). J. Biol. Chem. 55, 39.

Davidson, J.K., Falkmer, S., Mehrotra, B.K., Wilson, S., 1971. Insulin assays and light microscopical studies of digestive organs in protostomian and deuterostomian species and in coelenterates. Gen. Comp. Endocrinol. 17, 388-401.

De Loof, A., Claeys, I., Simonet, G., Verleyen, P., Vandersmissen, T., Sas, F., Huybrechts, J., 2006. Molecular markers of phase transition in locusts. Insect Sci. 13, 3-12.

Ding, J.L., Tan, K.C., Thangamani, S., Kusuma, N., Seow, W.K., Bui, T.H.H., Wang, J., Ho, B., 2005. Spatial and temporal coordination of expression of immune response genes during Pseudomonas infection of horseshoe crab, Carcinoscorpius rotundicauda. Genes Immun. 6, 557574.

Falkmer, S., Emdin, S., Havu, N., Lundgren, G., Marques, M., Ostberg, Y., Steiner, D.F., Thomas, N.W., 1973. Insulin in invertebrates and cyclostomes. Integr. Comp. Biol. 73, 625-638.

Fournier, B., Herault, J.P., Proux, J., 1987. Antidiuretic factor from the nervous corpora cardiaca of the migratory locust-improvement of an existing invitro bioassay. Gen. Comp. Endocrinol. 68, 49-56.

Gade, G., Hoffmann, K.H., Spring, J.H., 1997. Hormonal regulation in insects: facts, gaps, and future directions. Physiol. Rev. 77, 9631032.

Girardie, J., Boureme, D., Couillaud, F., Tamarelle, M., Girardie, A., 1987. Anti-juvenile effect of neuroparsin-A, A neuroprotein isolated from locust corpora cardiaca. Insect Biochem. 17, 977-983.

Girardie, J., Girardie, A., Huet, J.C., Pernollet, J.C., 1989. Amino-acid sequence of locust neuroparsins. FEBS Lett. 245, 4-8.

Girardie, J., Richard, O., Huet, J.C., Nespoulous, C., Van Dorsselaer, A., Pernollet, J.C., 1991. Physical characterization and sequence identification of the ovary maturating parsin. A new neurohormone purified from the nervous corpora cardiaca of the African locust (Locusta migratoria migratorioides). Eur. J. Biochem. 202, 1121-1126.

Girardie, J., Huet, J.C., Atay-Kadiri, Z., Ettaouil, S., Delbecque, J.P., Fournier, B., Pernollet, J.C., Girardie, A., 1998. Isolation, sequence determination, physical and physiological characterization of the neuroparsins and ovary maturing parsins of Schistocerca gregaria. Insect Biochem. 28, 641-650.

Hietter, H., Vandorsselaer, A., Luu, B., 1991. Characterization of 3 structurally-related $8-9 \mathrm{kDa}$ monomeric peptides present in the corpora-cardiaca of locusta - a revised structure for the neuroparsins. Insect Biochem. 21, 259-264.

Janssen, T., Claeys, I., Simonet, G., De Loof, A., Girardie, J., Vanden Broeck, J.V., 2001. cDNA cloning and transcript distribution of two different neuroparsin precursors in the desert locust, Schistocerca gregaria. Insect Mol. Biol. 10, 183-189.

Lagueux, M., Kromer, E., Girardie, J., 1992. Cloning of a locusta cDNAencoding neuroparsin-A. Insect Biochem. 22, 511-516.

Leroith, D., Lesniak, M.A., Roth, J., 1981. Insulin in insects and annelids. Diabetes 30, 70-76.

Lorenzen, M.D., Doyungan, Z., Savard, J., Snow, K., Crumly, L.R., Shippy, T.D., Stuart, J.J., Brown, S.J., Beeman, R.W., 2005. Genetic linkage maps of the red flour beetle, Tribolium castaneum, based on bacterial artificial chromosomes and expressed sequence tags. Genetics 170, 741-747.

Lorenzini, D.M., da Jr., S.P., Soares, M.B., Arruda, P., Setubal, J., Daffre, S., 2006. Discovery of immune-related genes expressed in hemocytes of the tarantula spider Acanthoscurria gomesiana. Dev. Comp. Immunol. 30, 545-556.

Ma, Z.Y., Yu, J., Kang, L., 2006. LocustDB: a relational database for the transcriptome and biology of the migratory locust (Locusta migratoria). BMC Genomics 7, 11 .

Monget, P., Besnard, N., Huet, C., Pisselet, C., Monniaux, D., 1996. Insulin-like growth factor-binding proteins and ovarian folliculogenesis. Horm. Res. 45, 211-217.

Moreau, R., Gourdoux, L., Girardie, J., 1988. Neuroparsin-a new energetic neurohormone in the African locust. Arch. Insect Biochem. Physiol. 8, 135-145.

Nagasawa, H., Guo, F., Zhong, X.C., Xia, B.Y., Wang, Z.S., Qui, X.J., Wei, D.Y., Chen, E.I., Wang, J.Z., Suzuki, A., Isogai, A., Hori, Y., Tamura, S., Ishizaki, H., 1980. Large scale purification of prothoracicotropic hormone of silkworm (Bombyx mori). Sci. Sin. 23, 10531060.

Nakakura, N., Hietter, H., Vandorsselaer, A., Luu, B., 1992. Isolation and structural determination of 3 peptides from the insect Locusta migratoria-identification of a deoxyhexose-linked peptide. Eur. J. Biochem. 204, 147-153.

Nene, V., Lee, D., Kang'a, S., Skilton, R., Shah, T., de Villiers, E., Mwaura, S., Taylor, D., Quackenbush, J., Bishop, R., 2004. Genes transcribed in the salivary glands of female Rhipicephalus appendiculatus ticks infected with Theileria parva. Insect Biochem. 34, 1117-1128.

Pener, M.P., Yerushalmi, Y., 1998. The physiology of locust phase polymorphism: an update. J. Insect Phys. 44, 365-377.

Plisetskaya, E., Kazakov, V.K., Soltitskaya, L., Leibson, L.G., 1978. Insulin-producing cells in gut of freshwater bivalve mollusks Anodonta-Cygnea and Unio-Pictorum and role of insulin in regulation of their carbohydrate-metabolism. Gen. Comp. Endocrinol. 35, 133-145.

Riehle, M.A., Brown, M.R., 1999. Insulin stimulates ecdysteroid production through a conserved signalling cascade in the mosquito Aedes aegypti. Insect Biochem. 29, 855-860.

Riehle, M.A., Garczynski, S.F., Crim, J.W., Hill, C.A., Brown, M.R., 2002. Neuropeptides and peptide hormones in Anopheles gambiae. Science 298, 172-175.

Stanke, M., Schoffmann, O., Morgenstern, B., Waack, S., 2006. Gene prediction in eukaryotes with a generalized hidden Markov model that uses hints from external sources. BMC Bioinform. 7, 62.

Tamarelle, M., Girardie, J., 1989. Immunohistochemical investigation of locust neuroparsin-like substances in several insects, in some other invertebrates, and vertebrates. Histochemistry 91, 431-435.

Tamarelle, M., Belles, X., Piulachs, D., Girardie, J., 1990. Gastrincholecystokinin-like and neuroparsin-like immunoreactivities in the brain and retrocerebral neuroendocrine complex of the cockroach Blattella germanica. Histochemistry 93, 433-438.

Tawfik, A.I., Mathova, A., Sehnal, F., Ismail, S.H., 1996. Haemolymph ecdysteroids in the solitary and gregarious larvae of Schistocerca gregaria. Arch. Insect Biochem. Physiol. 31, 427-438.

Tawfik, A.I., Vedrova, A., Li, W.W., Sehnal, F., ObengOfori, D., 1997. Haemolymph ecdysteroids and the prothoracic glands in the solitary and gregarious adults of Schistocerca gregaria. J. Insect Phys. 43, 485493.

Tawfik, A.I., Tanaka, S., De Loof, A., Schoofs, L., Baggerman, G., Waelkens, E., Derua, R., Milner, Y., Yerushalmi, Y., Pener, M.P., 
1999. Identification of the gregarization-associated dark-pigmentotropin in locusts through an albino mutant. Proc. Natl. Acad. Sci. USA 96, 7083-7087.

Tawfik, A.I., Treiblmayr, K., Hassanali, A., Osir, E.O., 2000. Time-course haemolymph juvenile hormone titres in solitarious and gregarious adults of Schistocerca gregaria, and their relation to pheromone emission, CA volumetric changes and oocyte growth. J. Insect Phys. 46, 1143-1150.

Towle, D.W., Smith, C.M., 2006. Gene discovery in Carcinus maenas and Homarus americanus via expressed sequence tags. Integr. Comp. Biol. 46, 912-918.

Vanden Broeck, J., 2001. Neuropeptides and their precursors in the fruitfly, Drosophila melanogaster. Peptides 22, 241-254.

Vanhems, E., Delbos, M., Girardie, J., 1990. Insulin and neuroparsin promote neurite outgrowth in cultured locust CNS. Eur. J. Neurosci. 2, 776-782.

Van Noorden, S., Falkmer, S., 1980. Gut-islet endocrinology-some evolutionary aspects. Invest. Cell. Pathol. 3, 21-35.

Wang, J., Jemielity, S., Uva, P., Wurm, Y., Graff, J., Keller, L., 2007a. An annotated cDNA library and microarray for large-scale gene-expression studies in the ant Solenopsis invicta. Genome Biol. 8, R9.

Wang, L., Wang, S., Li, Y., Paradesi, M.S., Brown, S.J., $2007 b$. BeetleBase: the model organism database for Tribolium castaneum. Nucleic Acids Res. 35, D476-D479.

Webb, R., Campbell, B.K., Garverick, H.A., Gong, J.G., Gutierrez, C.G., Armstrong, D.G., 1999. Molecular mechanisms regulating follicular recruitment and selection. J. Reprod. Fertil. 54, 33-48.

Weiss, I.M., Kaufmann, S., Mann, K., Fritz, M., 2000. Purification and characterization of perlucin and perlustrin, two new proteins from the shell of the mollusc Haliotis laevigata. Biochem. Biophys. Res. Commun. 267, 17-21.

Weiss, I.M., Gohring, W., Fritz, M., Mann, K., 2001. Perlustrin, a Haliotis laevigata (abalone) nacre protein, is homologous to the insulin-like growth factor binding protein $\mathrm{N}$-terminal module of vertebrates. Biochem. Biophys. Res. Commun. 285, 244-249.

Wilson, S., Falkmer, S., 1965. Starfish insulin. Can. J. Biochem. 43, 16151624.

Yoshimura, Y., 1998. Insulin-like growth factors and ovarian physiology. J. Obstet. Gynaecol. 24, 305-323. 